\title{
E-GOVERNMENT BUSINESS STRATEGIES AND SERVICES TO CITIZENS
}

An analysis of the Australian e-tax system

\author{
JEFF CHAMBERLAIN and TANYA CASTLEMAN \\ Deakin University, School of Information Systems, Australia
}

\begin{abstract}
Governments are pursuing initiatives to deliver their services on-line in order to provide better service to citizens as well as to reduce their own business costs. Designing good applications is not just a matter of developing good technical solutions. The context in which the application will be used is also important. One application with the potential to benefit both government and citizens is on-line lodgement of personal income tax returns. Properly implemented, this could mean considerable savings of time and administrative costs for the government and provide citizens with an inexpensive, convenient and speedy way to complete their annual tax obligations. This paper analyses the development and implementation of the Australian on-line tax lodgement system known as e-tax. Analysis of data from the Australian Taxation Office (ATO) identifies patterns of e-tax use, characteristics of users and the users' evaluation of the e-tax system. The analysis indicates that e-tax is successfully used by a growing number of tax payers but that the up-take rates of e-tax are lower than might be expected. The spread of e-tax will depend on more than just the viability of the technical product. The ATO will need to deal with a variety of complex contextual factors in its plans to promote e-tax. This analysis highlights some broader issues related to electronic service delivery (ESD) and eGovernment.
\end{abstract}

\section{INTRODUCTION}

In recent years governments around the world have embraced the opportunities offered by conducting business over the Internet. Informed by a policy framework that emphasises efficiency and effectiveness in the way governments conduct their business, millions of dollars have been allocated

The original version of this chapter was revised: The copyright line was incorrect. This has been corrected. The Erratum to this chapter is available at DOI: 10.1007/978-0-387-35692-1_36 
to developing new on-line business models and practices that promise reduced operating costs, enhanced citizen services, improved applications of scarce resources and the rapid processing of business transactions. This has stimulated the implementation of thousands of government web sites and Internet based business and communications systems across the globe. Several years of such innovations provide valuable insight, particularly in relation to the achievement of their intended effects and ultimate successes.

The Australian federal government promotes the use of the Internet as an efficient and effective medium through which to conduct business and communication. Through its 'Government On-line' policy it prescribes requirements for government departments to deliver various services electronically (Government Online 2000). Consistent with this policy direction, the Australian Taxation Office (ATO) has innovated in this area by developing a number of strategies to deliver services and administer business electronically.

This paper examines one of the ATO's recent electronic initiatives, an on-line lodgement system for individual taxpayers known as 'e-tax'. The uptake of e-tax has fallen far short of government projections, raising questions about its ability to meet its objectives and how well it fits with the needs of the taxpaying public. Our purpose in this paper is to analyse comprehensive ATO data on e-tax use in order to understand its potential and limitations as an ESD initiative. We identify the situational factors that have influenced the success of this initiative and consider the implications for eGovernment and electronic service delivery (ESD) initiatives more broadly.

\section{FACTORS IN GOVERNMENT ESD}

Governments of the world have implemented many forms of ESD including on-line systems for voting; administering compensation claims and premium payments; completing surveys; accessing public records and obtaining permits and licences. Delivery of such convenience to citizens online has arguably enhanced governments' relationships with their constituents. Additionally, many cost savings have been achieved such as reduced publishing expenses; reduced telephone, mail, and front desk customer enquiries; streamlined procurement processes; a reduced need for public servants to key paper forms; enhanced data analysis and even increased advertising opportunities (Carberry 2000; Nabers 2000; Public Management 2000; Thibodeau 2000; The Economist 2000).

There are two main goals underlying initiatives for government on-line service delivery. These are increased government openness including better 
provision of citizen services and business process improvement (Chamberlain and Castleman, 2001). The prevailing motivation for eGovernment initiatives appears to be their potential to improve business processes. eGovernment initiatives are seen to maximise business efficiency and effectiveness. Such improvements relate primarily to the delivery of services to the public and information dissemination, typical transactions performed by governments everyday (Public Management 2000).

Business efficiency and effectiveness can be measured principally against the reduced costs of administering citizen transactions. Reduced transaction costs are presented as major arguments by governments in justifying business cases for implementation of on-line innovations. In this way governments also exercise their accountabilities to the public by demonstrating the effective allocation of public funds (Girishankar 1997; Colecchia 1999). In addition to transaction costs, effective allocation should include other considerations such as potential rates of on-line product diffusion, marketing methods and change management if such calculations are to reflect realistic outcomes. Governments and their administrations will ultimately be judged by the public; it is crucial therefore that eGovernment innovations everywhere, be implemented only where positive and realistic outcomes are, on the balance of probabilities, expected (Caddy 1999). Citizens expect, on the one hand, governments to operate efficiently and on the other hand, they expect governments to provide universally accessible services in ways that meet citizen's needs. Governments therefore need to find a suitable balance between implementing business efficiency gains and improved service delivery.

The Australian federal government is a good example of a government that follows these principles for ESD. In 2000 it announced an Internet strategy called 'Government On-line' which recognises that its own transition to the on-line environment is critical to instilling public confidence in that environment. The strategy includes provision for security, authenticity, privacy, accessibility, navigability, and standards (Government Online 2000).

- The four stated objectives of the Australian Government's on-line strategy are: An environment where virtually all government services are available around the clock to anyone;

- A complete range of high quality, low cost on-line services;

- Tailored services that are easy to use and allow people to interact with government in a way which is natural to them; and

- Bringing government closer to people to encourage people to interact with government.

It is within this policy framework that e-tax has been developed. Before turning to an examination of the implementation of this product, it will be 
useful to have a brief look at e-tax and the context in which it has been introduced.

\section{E-TAX AND THE AUSTRALIAN CONTEXT}

Australians are required to report annually to the ATO on their personal income for the purpose of tax assessment. There have been two main ways of submitting these reports.

- They may lodge paper returns which must be submitted between July and

October. A kit of over 100 pages including forms and directions is available at newsagencies and ATO branch offices. The completed return is forwarded by post to an ATO branch office for processing which can take up to two months because ATO officers are required to check and key the information manually. The user is unlikely to receive a prompt refund. There is also a facility for electronic lodgement of paper returns through a post office.

- They may engage an accountant or tax-agent who will lodge using the secure ATO value added network (VAN). The ATO establishes a lodgement program with the tax professionals each year which extends beyond the July to October deadline required for other methods. To avoid late lodgement penalties, some individuals choose this lodgement method where they have been unable to complete their returns within the required time (ATO 2002).

Since 1999, taxpayers have had the option of e-tax. This secure, on-line tax return and lodgement program is downloaded by individual taxpayers from the ATO's Web site. It helps users determine whether they should lodge a tax return and, if so, asks a series of questions requiring user input to complete the actual return. A series of 'interview screens' guide users and intelligent rules built into the system ensure that only questions pertinent to each user are asked. The program includes worksheets for computations and various information and help screens. If they are entitled to a tax refund, users can elect to receive them via Electronic Funds Transfer (EFT). Users can print copies of completed returns for their records (McCarthy 1997; ATO 1997a; ATO 1997b; ATO 1998; ATO 1999a; Gliddon 2000). E-tax lodgement is available only from July to the end of October.

The e-tax program collates all of the typically required tax return data including information on the taxpayer's income, deductions, losses, tax offsets and rebates, the healthcare levy and any other adjustments. It also provides an estimate of the taxpayer's assessment (i.e., the dollar amount owing or refundable). Validation and consistency tests check the user's answers and figures and notifies her of incomplete items. 'Public Key' 
encryption technology is used to ensure the security, privacy, authenticity and integrity of the lodgement. Partly completed returns can be saved and several members of a household can use the software on the same computer after downloading their individual secure electronic keys and digital certificates.

In the original proof of concept documentation, business arguments presented in favour of the trial of the e-tax product included advantages for the service provider (ATO) as well as the tax payer. These included:

- the improvements brought to client assistance

- the ease of tax return preparation

- the speed of tax return preparation

- the reduction in compliance costs (for example, lodgement over the Internet), and

- a higher attainment of data quality by virtue of client keyed data and some software error checking (ATO 1997a)

These business arguments exemplify the efficiency and effectiveness objectives and rationales of governments when implementing such innovations. Efficiencies in this context related to such gains as expected reductions in processing and compliance costs and increased effectiveness in terms of client service and data quality. All arguments reflected the ATO's wider strategic plans in place at that time.

In the five years since e-tax was launched, a body of data on e-tax usage has been collected by the ATO. Our analysis uses this data to investigate the experience of the e-tax implementation to date and considers how successful the e-tax program has been in meeting its goals. We examine patterns of etax use to identify the factors which have influenced its adoption. More broadly, we look at how e-tax fits within the existing Australian taxation system and what Australia's e-tax initiatives suggests about government ESD initiatives and eGovernment.

\section{METHOD}

This analysis is based on tax lodgement data supplied by the ATO. This is a comprehensive set of de-identified national data for all personal income tax lodgements for the years 1998-2000 and is thus both complete and accurate. Although we had access to 2001 data, this was incomplete because returns submitted through tax agents were still permitted at the time the data was supplied. Most of our analysis in this paper is therefore based on data for 2000 .

A total of 415,436 e-tax records were analysed, each of which included indications of lodgement type, income, deductions and rebates and the 
amount of tax refund or liability resulting from the tax assessment. The records also included demographic variables including occupation, sex, Australian residency, age and residence (by postcode regions). Data was formatted in Excel spreadsheet databases and pivot tables with assistance from the ATO.

Data on users' experiences of e-tax was also made available. An optional electronic survey of 26 questions, delivered through the e-tax software, was introduced in the 2001. It is automatically sent to the ATO upon lodgement of the individual's income tax return. The survey explores the reasons for using e-tax and the user's satisfaction with the e-tax product. By mid October 2001, 20250 individuals had completed the survey in relation to the 2001 lodgement year (this constitutes an 18\% response rate). Summarised results of the survey were obtained from the ATO which we were able to analyse further for this study .

\section{FINDINGS}

In the 2000 tax year, 113,164 tax payers lodged their personal income tax returns using e-tax. This number was an increase from 26,015 in 1999 and grew to 273,952 in 2001 . While this represents a rapid growth rate, e-tax lodgements in 2001 were only about three-quarters of the ATO forecasts and e-tax lodgements are still only $1 \%$ of the over 10 million lodgements as shown in Figure 1.

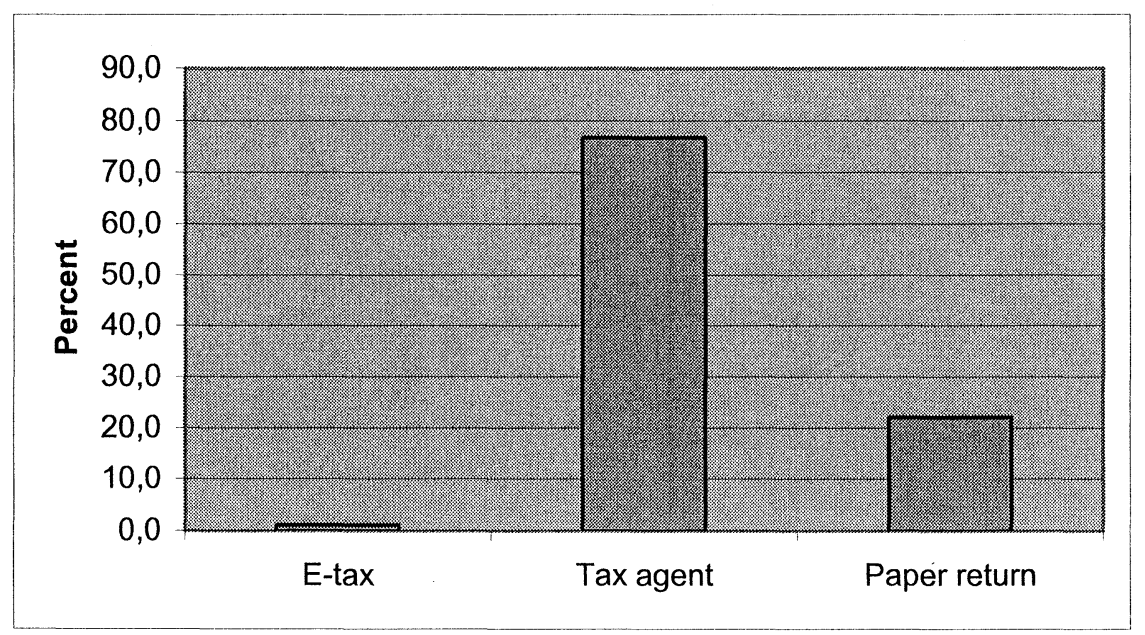

Figure 1. Methods of personal tax lodgement 2000 
The vast majority (77\%) of Australian taxpayers lodge their returns using the services of tax agents, with only $22 \%$ using paper returns. Lodgement types also reflect underlying differences in the two groups of taxpayers. As shown in Table 1, those using paper returns have, on average, lower incomes and fewer deductions than those using tax agents and claim a higher level of rebate (characteristic of lower income earners). The e-tax users have a profile much closer to that of tax payers who engage the services of tax agents than to those lodging paper returns.

\begin{tabular}{|l|l|l|l|}
\hline & e-tax & Tax agents & Paper return \\
\hline \hline Income or loss & $\$ 35,241$ & $\$ 34,563$ & $\$ 24,360$ \\
\hline Deductions & $\$ 1,351$ & $\$ 1,787$ & $\$ 856$ \\
\hline & & & \\
Tax offsets and rebates & $\$ 730$ & $\$ 808$ & $\$ 818$ \\
\hline
\end{tabular}

Table 1. Mean Income, Deductions and Rebates per lodgement method in 2000

Source: ATO Environmental Monitoring System, Australian Taxation Office, November 2001.

How can we understand why the rate of uptake of e-tax lags behind ATO projections, despite its apparently high level of functionality? There are a number of reasons that might make e-tax less attractive than other lodgement methods and we investigate these possibilities by comparing data on the characteristics of e-tax users with other tax-payers.

\subsection{Does the e-tax lodgement method work well enough?}

The e-tax survey feedback is largely positive and when asked if they would use e-tax again in the 2002 year, $94 \%$ of respondents stated that they would. The remaining $6 \%$ were undecided. Most of these respondents were first time users; $67 \%$ of respondents had not used e-tax in the previous year. In response to the question, 'How satisfied or dissatisfied were you with etax?', $47 \%$ of respondents indicated that they were 'very satisfied' whilst a further $46 \%$ stated they were 'satisfied' (an over $90 \%$ satisfaction rate among the survey respondents). The e-tax product appears to be popular with the vast majority of its users who reported no significant technical problems either with downloading or lodgement. 


\subsection{Is e-tax too time-consuming and inefficient?}

There is no indication that this is the case. In completing a personal income tax return using the e-tax software the user is 'interviewed' and is required to respond to a series of relatively straight forward questions with 'yes' and 'no' answers, not unlike responding to an expert system. The e-tax system analyses responses as it receives them and proceeds by asking the user only those questions pertinent to that user's tax affairs. This aids in the speed and accuracy of the completion of the return; in contrast, those using the paper kit must work through over one hundred pages of literature. Survey feedback revealed that $91 \%$ of respondents were either 'very satisfied' or 'satisfied' with the e-tax interview method. Eighty nine per cent of respondents considered this to be a 'very important' or 'important' feature of e-tax. Anecdotal evidence suggests that e-tax preparation can be completed in as little as half the time required for paper returns.

\subsection{Is e-tax too complicated for the average taxpayer?}

It is possible that e-tax is complicated and requires skill and education levels beyond those of most of the population. Survey questions related to the package's ease of use drew positive responses. Eighty per cent of respondents were either 'very satisfied' or 'satisfied' with the ability to locate e-tax on the ATO website and $90 \%$ believed that this was either a 'very important' or 'important' feature. Eighty seven per cent of respondents were either 'very satisfied' or 'satisfied' with the task of downloading the etax software from the Internet, whilst $81 \%$ indicated that they were 'very satisfied' or 'satisfied' with downloading the e-tax security software. Navigation scored an $85 \%$ approval rating and $91 \%$ were satisfied with the question-answer format of the product.

We also examined the occupations of e-tax lodgers on the premise that occupations are related to education and reflect, at least in broad terms, a taxpayer's ability to use complicated IT tools. Occupations were categorised as 'professional' or 'non-professional' from a list of 300 occupational descriptions. Examples of occupations considered to hold a professional status include judges, managers, scientists, teachers, lawyers and business professionals. Examples of occupations allocated a non-professional status include hairdressers, cabinet makers, sales representatives, taxi drivers, and construction workers.

The growing proportion of non-professionals among e-tax users indicates that the product is suitable for ordinary taxpayers. Analysis over the three lodgement years reveals a gradual decline in the proportion of e-tax users who were professionals from $43 \%$ in 1999 to $31 \%$ in 2001 . Non- 
professionals increased from $57 \%$ to $65 \%$ of e-tax users over the same period. The remaining respondents did not state their occupations.

\subsection{Is e-tax only attractive to people who want a quick refund?}

It is not uncommon for taxpayers to receive a refund at the end of each financial year. An advantage of e-tax is the speed with which a tax return can be lodged and a refund provided. We might expect that this method of lodgement will be particularly attractive to taxpayers expecting to receive a refund and of much less interest to those who expect to pay additional tax. The speed of refund is likely to be a factor in e-tax use since an analysis of refunds revealed that most e-tax lodgers receive a tax refund. Figure 2 shows the patterns of refunds and debits for all e-tax users over the three years 1999-2001. Since the great majority $(86 \%)$ of e-tax users gained a tax refund, the speedy lodgement and return process facilitated by e-tax is a significant incentive.

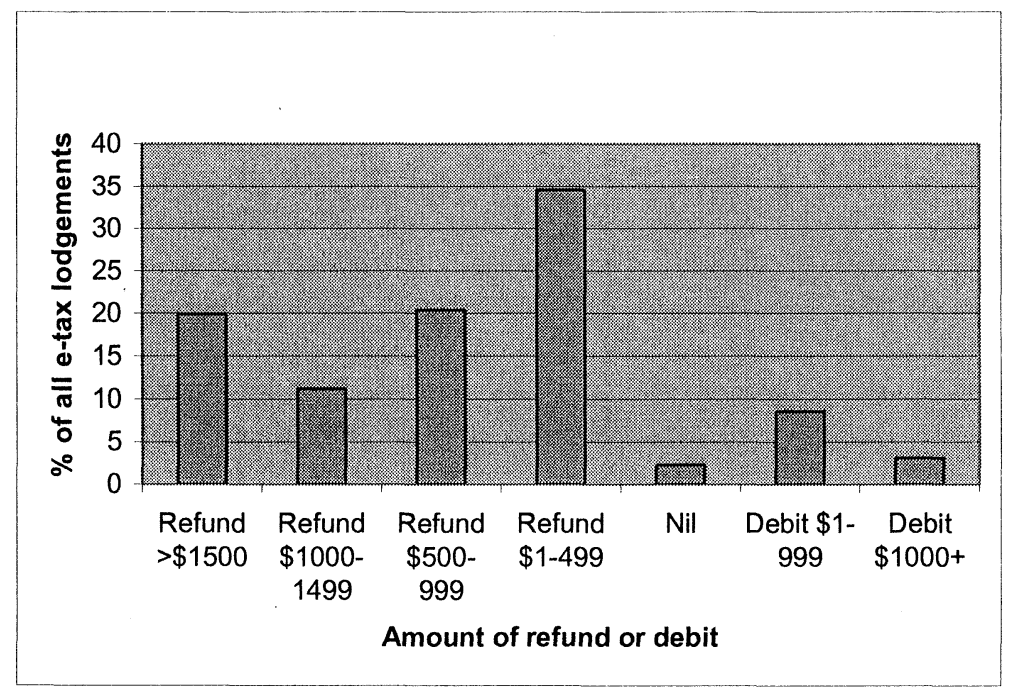

Figure 2. e-tax assessment outcomes 1999 - 2001

Source: ATO Mainframe data extract, November 2001

The survey data, however, indicate that convenience was even more important than getting a 'fast refund'. Respondents were asked to indicate the importance of various factors considered to be motivators for e-tax 
adoption. The distribution of survey responses shown in Figure 3 shows the percentage of respondents who considered these 'very important' and 'important' as motivators to their use of the e-tax innovation.

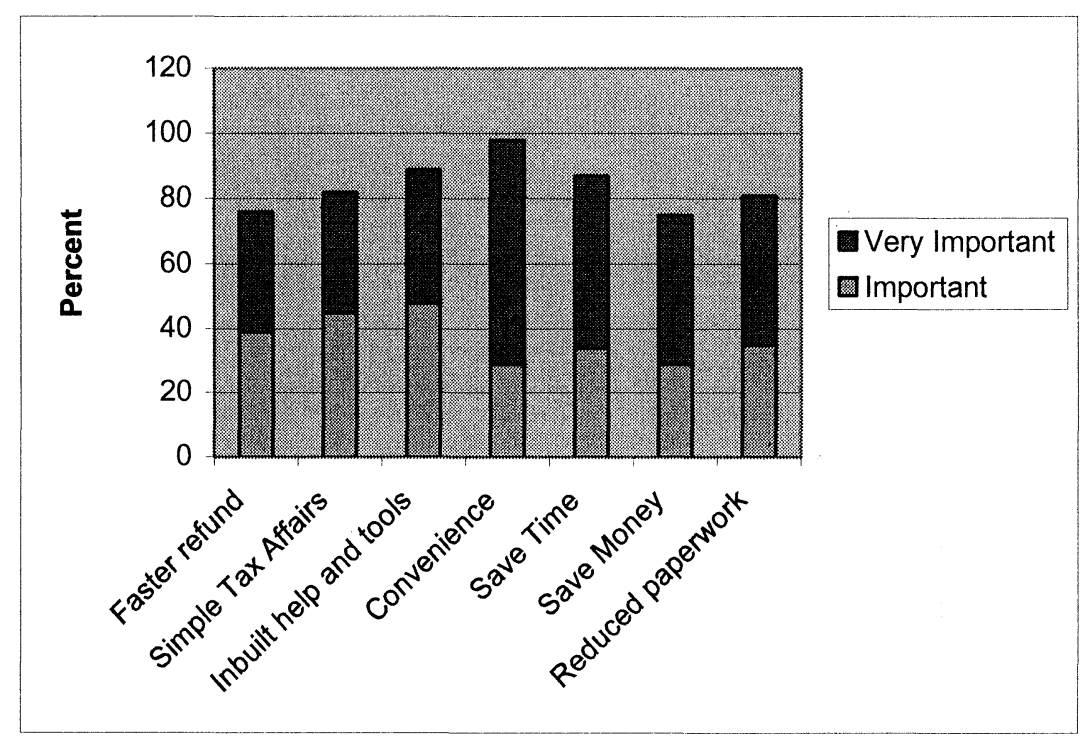

Figure 3. Reasons for using e-tax

Source: E-Tax 2001 User On-line questionnaire summary as at $15^{\text {th }}$ October, 2001, Australian Taxation Office.

It is interesting to note that overall, saving money and accessing faster refunds are rated least important (though still representing a sizeable majority of users). 'Convenience' was the most common reason $(98 \%$ of respondents cited this) followed by access to instant on-line help and tools offered in the e-tax product (89\%) and the time-saving benefits of e-tax $(87 \%)$.

\subsection{Is e-tax inadequate for more complex tax issues?}

It may be that e-tax is either not able to deal with higher levels of complexity in tax matters or that it is perceived as being inadequate for these purposes. It is true that e-tax does not cater for those required to complete the more complex types of income tax returns (e.g., more non-salary income relating to companies, funds, partnerships and trusts) but this would not 
account for the large difference between the level of e-tax use and those choosing to use tax agents. There is no direct measure of income tax complexity available for this analysis but we can reason that people with higher incomes and those who claim more deductions will have more complex tax affairs.

The data presented in Table 1 showed that e-tax users had relatively high median incomes compared with those using the paper return and those using tax accountants. This may indicate that e-tax is likely to be suitable for those with more complex tax affairs. However, e-tax users claimed a lower level of deductions than those using tax agents which would suggest that their tax arrangements are indeed less complex. The decision to use a tax agent, of course, may reflect not an inherent taxation complexity but the tax agents' ability to identify more or larger deductions than the taxpayer is able to do.

Survey figures give further insight on this point. Eighty-two per cent of respondents said that they used e-tax because their tax affairs were simple and straightforward. We conclude that while the e-tax application is not able to deal with very high levels of complexity, it can cope with a fair range of tax issues and that the users seem satisfied.

\subsection{Does e-tax prevent taxpayers from maximising their tax deductions?}

There is some support for this view. As indicated above, by far the most common form of lodgement is via tax accountants who provide advice in addition to filling out and lodging the returns. (Most lodge the returns they prepare for clients electronically via a VAN). Engaging an accountant provides the taxpayer with an added assurance that all tax deductions available to individuals have been considered and included in income tax returns where possible. The figures presented in Table 1 above reveal that lodgements through tax agents contain the highest average level of claims for deductions of the major lodgement methods. These figures in Table 1 above suggest that using tax accountants does help tax payers increase their deductions, thus reducing their tax liability.

If it is the case that tax agent lodgements are more effective in increasing tax deductions, this will diminish the attractiveness of e-tax. Even though etax may provide users with prompts to alert them to the deductions that they might claim, it may not be able to match (or may not be perceived to match) the ability of tax accountants to identify allowable deductions. 


\subsection{Has e-tax been poorly publicised or promoted?}

It is possible that the reason many taxpayers do not use e-tax is that they are not aware of it or find it difficult to locate the web site to access it. An ATO marketing strategy document prepared in April 2001 reveals that the 'growth in use of e-tax has occurred with only moderate promotion mainly through 'business as usual' ATO channels. Examples of such channels include counter and telephone enquiries and advertising within the paperbased tax kit literature and other brochures. The e-tax on-line survey reveals that $37 \%$ of users either heard or learned about e-tax via advertising in the tax kit. Figure 4 reveals the sources from which users heard about or learned of e-tax for the 2001 lodgement year.

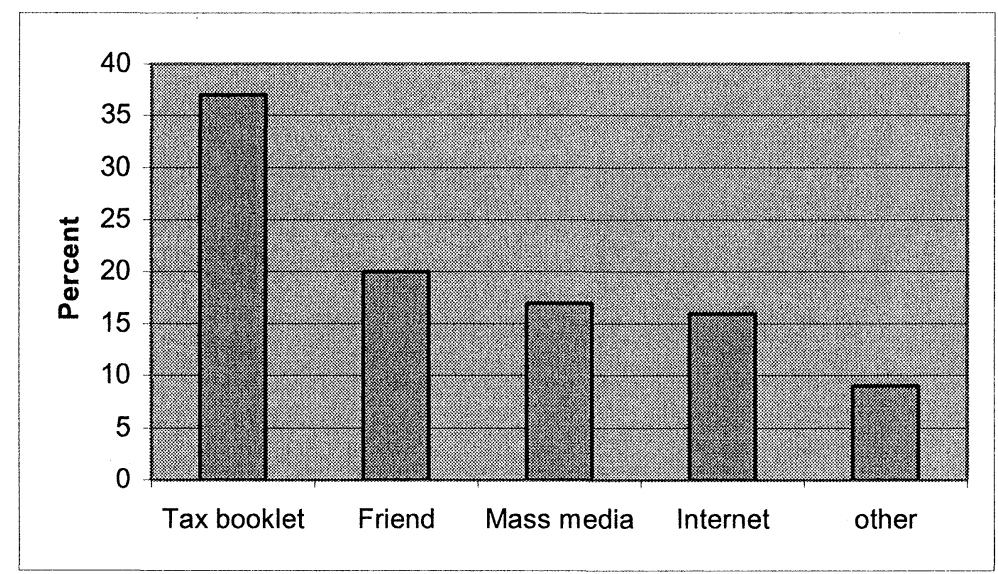

Figure 4. How users learned about e-tax - 2001

Source: ATO, e-tax User Survey, 2001

The fact that so few e-tax users learned about it through the mass media indicates that the publicity strategy for e-tax is inadequate and that it is not sufficiently promoted through public channels. The majority of users found out about it through what appear to be mainly adventitious processes. Without a public information campaign, it is unlikely that the diffusion rate of e-tax will rise swiftly. This finding also suggests, however, that a welldesigned public information campaign could lift the use of e-tax considerably. 


\section{DISCUSSION}

Our examination of e-tax concludes that it is a well developed, high quality product that works well and meets the Government's objective of providing high quality on-line services. It is freely available over the Internet and can be downloaded securely via the ATO's web site. It is arguable, however, whether the e-tax product can be considered a low cost, on-line service. Heavy costs must be borne by the ATO to sustain the product's life and whilst e-tax is offered free to taxpayers, a series of typically hidden client costs are also beginning to emerge, such as the need for a private ISP account, ISP download charges and download time as well as hard disk space requirements (ATO 1999c; Gliddon 2000; Madden 2000; Petrillo 2000; Preston 2000; Thomas 2000; Walker 2000; Fitzsimmons 2001; Neff 2001; NOIE 2001a; NOIE 2001b).

Costs incurred by the ATO include those associated with the development and currency of the product; technological and infrastructure requirements; project management and administration; and marketing and communications (ATO 1999b; Thibodeau 2000; ATO 2000a; ATO 2000b). Although we were not able to determine actual project costs, a project of this magnitude could cost several million dollars. This, coupled with a relatively small user base gives rise to a relatively high transaction cost. For example, a conservative estimate of say, A $\$ 3$ million for total e-tax expenses in the 2001 year against the 2001 user uptake of 273,852 individuals, equates to a very high cost of $\$ 10.95$ per transaction. This poses a problem in that e-tax as an electronic initiative should offer cost savings but may, at least in the short term, add to costs. It is unlikely that such a movement in estimated transaction costs would be endorsed in any business case for innovation as such costs, in an eGovernment project, would represent an ineffective allocation of public funds. However, it may be defensible as part of Government's other goals, viz, provision of services to citizens and leaders in the movement to an on-line environment.

The implementation of e-tax illustrates the kinds of quandaries that can confront governments, even when they pursue reasonably straightforward initiatives and where the technical systems work well. We have identified several issues that governments must deal with.

\subsubsection{Managing complex sets of requirements among different groups of clients}

The patterns of e-tax adoption clearly show that this mode of lodgement is appropriate only for taxpayers with access to the internet and with the IT skills to allow them to use it with confidence. Those lodging paper returns 
will often be people who have little prospect of being able to manage e-tax, either because of their income and education levels or because of their unfamiliarity with the Internet. Over the long term, the lack of IT skills and internet connection should decline as a barrier to the use of e-tax but this will not be a quick process. There will, arguably, always be a need to provide the option of paper-based returns, at least at the taxpayer end. Taxpayers who are unable to use e-tax will include many elderly and disabled people as well as those without computer access. Since potential e-tax users will need to be recruited from current paper users, this goal will be increasingly difficult to achieve. E-tax users currently are more similar (in income and demographic terms) to taxpayers who lodge via tax agents, yet e-tax cannot provide the same level of tax advice and assistance as the professional accountant. What advantage lies in encouraging tax payers to use e-tax rather than tax accountants? Because accountants lodge returns electronically, there is no reason for the ATO to encourage their clients to move to e-tax to enhance government business efficiency. However, having implemented the e-tax system, it must be continued if the government is not to disadvantage tax payers who prefer to lodge their own returns electronically. Ironically, the ATO may face the choice of either disadvantaging e-tax users (if the system is discontinued) or sustaining an uneconomic channel.

\subsubsection{Managing ESD in light of different stakeholder interests}

Aggressive moves to recruit taxpayers to e-tax from among those who currently use tax agents would clearly be inappropriate. Not only are there no business advantages for the ATO, but it would be highly inflammatory to take on such an influential professional group and threaten their livelihood. While a number of taxpayers may switch to e-tax from tax accountants, it is unlikely that this will be publicized or promoted by members of the industry themselves. As with so many other eCommerce issues, governments must tread a thin line in balancing their own interests with the business interests of the private sector. There is potential for government on-line initiatives to have consequences for the commercial market that were not anticipated.

\subsubsection{Effective and feasible strategies for promoting electronic and on-line channels for business between government and citizens}

One of the clear findings from our analysis was that the promotion of etax was ineffective and could be enhanced to recruit more users. Lack of publicity about the product and the incentives for using it probably 
contributed to its disappointing usage rates. One can imagine an advertising campaign or even an incentive scheme to increase e-tax use. If this campaign were to encourage a shift from paper returns, all the ramifications are likely to be positive, even if there are limits to the number of people who are capable of shifting. However, any significant inroads into the clientele of tax accountants is, as pointed out earlier, likely to create difficulties for the ATO. If a good business case were to be made for such a campaign, the costs of that campaign would need to be outweighed by the efficiency gains of a significant increase in e-tax uptake.

\subsubsection{Adjustments in administrative processes and/or legal requirements to facilitate the move to ESD}

E-tax predominantly services those individuals seeking speedy return processing and tax refunds. Only a small minority of e-tax users are required to pay more tax following lodgement of their returns. This brings into question the real need for individuals to lodge income tax returns in the first instance, at least by those individuals expecting to receive refunds. The ATO has already received tax revenue from this group. Should legislation be revised to alter the existing lodgement paradigm, for example, eliminating the need for individuals to lodge income tax returns at all? In scoping business change for efficiency and effectiveness, eGovernments should eliminate all unnecessary processes, in particular administrative transactions. Should an eGovernment business process improvement exercise, in the first instance, comprehensively question the existence of, and need for, an existing process by weighing it against transaction costs and other variables, and then eliminating it before even proceeding with the development of reengineered on-line solutions?

\subsubsection{The policy and political issues in balancing the dual goals of improved services to customers and increased business efficiency}

Do the actual and perceived efficiencies of the e-tax product outweigh and justify the expensive maintenance and preservation of it? Should a high quality, on-line product be maintained to serve a fortunate minority at an unrealistic cost per transaction to sustain a philosophical construct founded upon the notion of democratic process fuelled by the hope of increased online interaction between government and citizens? Should a merging of technologies be considered, for example, synthesising the tax agent VAN and e-tax technologies and methods into a single lodgement channel with a view to consolidating development and maintenance expenses? Does 
eGovernment threaten or enhance democratic process, particularly increased government openness, by reducing administrative channels through consolidation, thereby forcing user fit but offering consistency in approach to a wider population?

\section{CONCLUSION}

Our purpose in this paper was to analyse comprehensive ATO data on etax use in order to understand its potential and limitations as an ESD initiative. Our findings show that despite disappointing uptake levels, e-tax performs well and is popular with its users. But there are questions about its appropriateness and attractiveness to a wider group of taxpayers. Various factors in the Australian taxation context have influenced the success of this initiative, including the heavy use of tax agents and the lack of access to computer and internet facilities by a significant proportion of the tax-paying population. This case shows clearly the conflicts that may arise between government goals of improving their own business efficiency and their obligations to a variety of stakeholder groups in the population. In the case of e-tax, efficiency goals suggest that either some degree of coercion is required to achieve an economic use of e-tax functionality or that e-tax itself should be abandoned as an uneconomic product. Either of these raises policy and political problems.

Governments will continue to search for business process efficiencies and effectiveness and will embrace the Internet wherever feasible to do so. The key is to do this without compromising its obligations to its citizens, whilst maintaining accountability for implementing efficient, effective, risk managed innovations that deliver publicly accessible, affordable, simple and necessary services.

\section{REFERENCES}

ATO, 1997a, 'EPack pilot planned for October', The ATO Updater Online, Jul/Aug 1997.

ATO, 1997b, 'e-tax trial scheduled for October', The ATO Updater Online, July 1997.

ATO, 1998, 'Epack gets go ahead for Taxtime 98', The ATO Updater Online, Feb 1998.

ATO, 1999a, 'e-tax ready for 1999 tax season', The ATO Updater Online, Apr 1999.

ATO, 1999b, A new tax office for a new tax system, Australian Taxation Office, May 1999,

ATO, 1999c, Tax and the Internet, Australian Taxation Office, 1999,

ATO, 2000a, Online eBusiness Strategy, Version 2.2, Australian Taxation Office, Sept 2000, ATO, 2000b, 'ATO prepares for E-commerce prime time', The ATO Updater Online,Feb 2000 . 
ATO, 2002, Tax Return Deadline Approaches, Media Release - Nat 2000/95, http://www.ato.gov.au/content.asp?doc=/content/Corporate/mr200095.htm, Last Accessed, $11 / 02 / 2002$,

Caddy, J., 1999, 'Engaging the citizen leads to better results', Public Management Forum, vol. 5 , no. 3 .

Carberry, J., Steins, C., 2000. 'G2B Web Sites', Tech Trends, Nov/Dec 2000, p.20-24.

Chamberlain, J., Castleman, T., 2001. National Governments doing business on-line: An Australian look at current practice and future hazards. Sixth CollECTeR Conference on Electronic Commerce, Dec. 3-4,2001 Coffs Harbour, Australia.

Colecchia, A., 1999, Defining and measuring electronic commerce. Towards the development of an OECD methodology. Conference on the measurement of electronic commerce, Singapore, Organisation for Economic Co-operation and Development.

Fitzsimmons, C., 2001, 'E-tax takes a commercial turn', 'The Australian'.

Girishankar, S., 1997, 'Feds get down to business with latest E-commerce push', Internet Week,No. 688. p.18-19.

Gliddon, J., 2000, 'E-tax spells tax easy', Bulletin with Newsweek, Vol. 118, No. 6230. p.83.

Government Online, 2000, Government Online - The Commonwealth Government's Strategy, Department of Communications Information Technology and the Arts, April 2000,

Madden, B., 2000, 'TaxPack goes online', Personal Investor, Vol. 18, No. 6. p.11.

McCarthy, J., 1997, 'Electronic Tax Pack to be piloted during 1997', The ATO Updater Online, Feb/Mar 1997.

Nabers, M. S., 2000, 'E-government portals open doors for business', Austin Business Journal, p.38.

Neff, D., 2001, 'Connecting citizens to government online', San Diego Business Journal, Vol. 22, No. 23. p. 14.

NOIE, 2001a, Access and Equity, National Office for the Information Economy, http://www.noie.gov.au/projects/access/index.htm, Last Accessed, 07/06/2001,

NOIE, 2001b, Equitable Online Access, National Office for the Information Economy, http://www.noie.gov.au/projects/access/online_access/index.htm, Last Accessed, 07/06/2001, Petrillo, J. J., 2000, 'Government's use of web has winners and losers', Government Computer News, Vol. 19, No. 5. p. 24.

Preston, M., 2000, 'E-Government US-Style', New Statesman, Vol. 129, No. 4517.

Public Management, 2000, 'A guide to e-government and e-commerce', Public Management, vol. 82, no.7. p.1.

The Economist, 2000, 'Quick Fixes', The Economist, vol. 355, no. 8176. p13.

Thibodeau, P., 2000, 'E-Government spending to soar through 2005', Computerworld, vol. 34, no.17. pp. 12-13.

Thomas, T., 2000, 'High hopes for online tax returns', Business Review Weekly, Vol. 22, No. 25. p.82.

Walker, R. W., 2000, 'Many govt. sites don't heed users' needs, study finds', Government Computer News, vol. 19, no. 16. p. 57. 